\title{
From ape empathy to human morality?
}

\author{
Article
}

Accepted Version

Borg, E. (2014) From ape empathy to human morality?

Analysis, 74 (4). pp. 577-587. ISSN 1467-8284 doi: https://doi.org/10.1093/analys/anu080 Available at https://centaur.reading.ac.uk/37482/

It is advisable to refer to the publisher's version if you intend to cite from the work. See Guidance on citing.

To link to this article DOI: http://dx.doi.org/10.1093/analys/anu080

Publisher: Oxford University Press

All outputs in CentAUR are protected by Intellectual Property Rights law, including copyright law. Copyright and IPR is retained by the creators or other copyright holders. Terms and conditions for use of this material are defined in the End User Agreement.

\section{www.reading.ac.uk/centaur}

\section{CentAUR}

Central Archive at the University of Reading

Reading's research outputs online 


\title{
From ape empathy to human morality?
}

\begin{abstract}
:
The idea that empathy provides an important developmental precursor to moral decision making possesses significant conceptual appeal. However, the idea of a necessary, diachronic relation between empathy and morality has been rejected recently (by Prinz 2011, amongst others). This paper reassesses the strength of the claim that empathy is developmentally necessary for (at least some forms of) morality and argues that the position remains a live possibility.
\end{abstract}

Keywords: empathy, morality, prosocial behaviour, infant development. 


\section{From ape empathy to human morality? ${ }^{1}$}

\section{1) Introduction}

The idea that empathy provides an important developmental precursor to moral decision making possesses significant conceptual appeal. However, the idea of a necessary relation between empathy and morality has been rejected recently. For instance, Jesse Prinz (2011) poses the question 'Is empathy necessary for morality?' and he suggests that there are three ways one might give a positive answer to this question:

i. empathy is necessary for moral judgement

ii. empathy is necessary for moral development

iii. empathy is necessary for moral motivation

He then argues against each of (i-iii) and concludes that empathy is not necessary for morality (though other emotional states may be). In this note I want to re-evaluate the case for position (ii) and suggest that it remains a live possibility.

\section{2) The case against empathy as necessary for moral development}

Empathy is closely related to emotional contagion on the one hand and perspective taking on the other. It involves feeling what another is feeling, a vicarious experience of a situation as if one were in the place of another (see Decety and Lamm 2006 for a useful comparison of various definitions of empathy). Due to its connection with emotional contagion - the well-attested phenomenon whereby we 'catch' the elements of our own emotional state from the emotional states of those around us (see Simner 1971, Thompson 1981) - it seems at least prima facie plausible to think of empathy as a quite low-level, cognitively undemanding capacity, and thus it

\footnotetext{
${ }^{1}$ Thanks are due to my colleagues in the Philosophy Department and in the Centre for Cognition Research at Reading, and to an anonymous referee for helpful comments and suggestions.
} 
might be thought to provide a developmental route into more sophisticated perspective-taking tasks and the more abstract or impartial concerns which are the hallmark of some kinds of moral reasoning. ${ }^{2}$ Prinz defines position (ii) as "the possibility that empathy plays a diachronic role: [empathic] emotions may be necessary for the development of the capacity to make moral judgements in the first place" (2011: 217), so empathy provides an answer to the question of what allows a child who lacks a moral capacity to develop a moral capacity. ${ }^{3}$ Of course, this position makes no prediction about the role of empathy in any specific exercise of the moral capacity itself once it has developed (unlike positions (i) and (iii) above). Thus, as Prinz points out, position (ii) is difficult to test experimentally. Discovery of a given instance of moral judgement without empathetic reasoning would not disprove (ii) but, on the other hand, even if we discovered that children typically did engage in empathetic reasoning when making moral judgements, this would only show a correlation between empathy and moral judgements, it would not show there was a causal or necessary relation between the two. Instead, then, Prinz suggests that advocates of (ii) should look to pathological cases for empirical support for their view, for if empathetic capacities are lost or impaired (ii) predicts that moral capacity will be similarly lost or impaired.

In this respect, Prinz examines work from Blair 1995 which looks at moral development in psychopaths. Psychopathic conditions are characterised by a lack of empathy and Blair shows that moral understanding in this population is also compromised, thus loss of empathy correlates

\footnotetext{
${ }^{2}$ As a reviewer pointed out, the extent to which empathy can be thought of as a relatively low-level capacity is open to question since, unlike emotional contagion, empathy does seem to be sensitive to higher-order metalizing; for instance, empathic reactions may be affected by a subject's understanding of a social situation. (On this point, it is interesting to note that the same holds for other putatively low-level interpersonal states, such as mirroring or imitation. As Piotr Winkielman has shown, though we often mirror one another in terms of bodily posture, facial expression, etc., this mirroring is sensitive to apparently higher-order mental states, such as the subject's beliefs about the power relations in play - we are more likely to mirror some individual $\mathrm{X}$ if we believe $\mathrm{X}$ is of high-status in the context.) Clearly, then, to fully substantiate the view that empathic responses could be a more basic developmental pre-cursor to moral reasoning further work on the relationship between empathy and theory of mind would be needed. Unfortunately, however, this is beyond the scope of the current note.

${ }^{3}$ Note that position (ii) need not be committed to the view that empathy is necessary for all forms of moral development. For instance, it might be held that prohibition moral reasoning (where sanctions and rules are to the fore, see below) can develop without empathy, while prosocial moral reasoning demands empathy. It is this weaker position - that empathy is necessary for at least some forms of moral development - that I will focus on in what follows.
} 
with impairments in moral development. This leads Blair to a positive claim about the developmental relationship between empathy and morality: he holds that typically developing children have an innate tendency to empathize with the distress of conspecifics and thus are disposed to 'feel bad' when they witness the suffering or distress of another. This bad feeling, Blair suggests, acts as a 'violence inhibition mechanism', causing a subject to desist from actions which cause distress and, in general, to associate bad feelings with actions of this kind. In this way, the claim is, distress gets associated with moral rules about prohibited or bad behaviour.

Prinz then goes on to reject Blair's view on the following grounds:

1) It is not clear that there is such thing as a 'violence inhibition mechanism'.

2) Many of the moral behaviours we learn involve non-violent behaviours (e.g. don't lie), thus a violence-inhibition mechanism cannot be at the heart of them.

3) Typically developing children draw the moral/conventional distinction well before they associate empathy with morality, so empathy can't ground moral understanding.

4) While it is true that pathological cases characterised by a lack of empathy (i.e. psychopathy) also show a marked inhibition of moral understanding, these deficits may be two down-stream results of a more general impairment, rather than standing in a causal relation to one another.

Prinz's final conclusion on position (ii) is then that:

Given the availability of this alternative explanation [in (4)], Blair's hypothesis that empathy is necessary for moral development is in need of further support. And given the fact that empathy enters into moral discourse fairly late in development, this alternative explanation is to be preferred. Young children are empathetic, but there is little evidence linking their empathetic responses to their capacity to make moral judgements. (218)...[Overall] the hypothesis that empathy is necessary for moral conduct - or even important - enjoys little support. (222).

So, should we accept Prinz's negative conclusion that empathy is not necessary for moral development? Well, a first point to note is that, of the four objections Prinz gives, objections (1) and (2) challenge only Blair's specific version of position (ii). An alternative account of the 
mechanism by which morality and empathy are connected (i.e. not in terms of a 'violence inhibition mechanism') might well avoid these two objections (I'll return to the possibility of such an alternative mechanism in \$3). It is objections (3) and (4) then which provide the real challenge to position (ii).

Yet objection (3), which obviously has wider appeal than (1) and (2), is given only very brief support in Prinz's paper. He notes work from Smetana \& Braeges 1990 showing sensitivity to the moral/conventional distinction before children are 3 years old, and work from EisenbergBerg 1979 which, it is suggested, "shows that empathy does not enter actively into moral reasoning until high school" (i.e. after age 13); Prinz 2011: 218. If this is correct, it does indeed seem to show that empathy cannot ground moral reasoning, since moral reasoning is active well before empathy is linked to it. However, I think there are reasons to question this interpretation of Eisenberg-Berg's work.

In the experiment conducted in Eisenberg-Berg 1979, 125 elementary and high school children in the US were given four stories (the stories were read to the children while they were also able to look at a written version) in which the child had to decide how a subject should act in a situation where the subject's needs or desires conflicted with the needs or desires of a target. Children were asked how the subject should act and why, and their answers were coded according to the kind of answer and reason given (e.g. the extent to which the answer involved empathic reasoning, needs-orientated reasoning, reciprocation-based reasoning, hedonistic concerns, etc.). The findings revealed that the older high school children used strongly empathic reasoning more than the younger elementary school children: "Stereotyped images of good and bad persons and interpersonally or approval-orientated moral reasoning decreased in frequency with age, whereas clearly empathic considerations and judgements reflecting internalised values increased with age" (1979: 135).

However it seems possible that the experimental structure used by Eisenberg-Berg, which placed quite a high cognitive load on participants, could have served to depress empathic 
responses in younger children. Just as paradigm false belief tests are now often held not to be revelatory of children's theory of mind capacities, instead revealing limitations in children's ability to comprehend and respond to complex linguistic tasks (see, e.g., Bloom \& German 2000, Onishi and Baillargeon 2005), so we might think that the methods of probing the nature of moral decision making utilised by Eisenberg-Berg do not reveal the true extent of empathic reasoning in moral decision making amongst young children, instead revealing something about the ability of children under the age of 13 to conceptualise, comprehend and respond to complicated experimental loads. For all four of the stories used required quite a substantial act of mental projection: the children were first required to put themselves into the shoes of the (adult) protagonist of each story, and then from that perspective assess whether or not the targets exerted an empathic pull on the subject. The experiments also required an empathic response to an imagined, and often abstract, other, rather than to a visually presented real subject (so any aspect of automatic emotional contagion was missing from the scenarios presented). This again might be thought to serve to supress empathic responses in younger children.

For instance, in one story, a poor village with just enough food to feed itself was asked to give food to a neighbouring village which had lost all its crops to flood; children were then asked 'what should the poor village do?'. However, this is far removed from the kind of immediate response to another where empathy has its most natural home: those in need are abstract, faceless others and the unit to help them is not a single individual but the village as a whole. It would be unsurprising if this kind of scenario failed to elicit empathy-based moral reasoning amongst young children, whose 'empathy-circle' as it were (i.e. the cases where the needs of another elicit empathy), may initially be quite small (with the idea that those we don't know and can't see can and should elicit our empathy being a significant cognitive achievement rather than an immediate empathic response). As noted at the outset, an advocate of position (ii) does not need to hold that any given moral judgement must involve an act of empathy - once moral reasoning is up and running, subjects may exercise their moral capacity with no appeal to 
empathy - and it may well be no surprise that the village scenario is one where young children deploy non-empathetic means to arrive at a moral judgement. ${ }^{4}$

To really assess the extent to which young children do use empathic responses as part of their moral reasoning, experimental prompts must control for conflating features which might otherwise disguise empathic reasoning. ${ }^{5}$ So, test scenarios should mirror normal, age-appropriate situations which the children might actually encounter and they should engage the child herself as agent, rather than requiring mental projection to an alternative subject. It would also be more appropriate for scenarios to provide a visual presentation of the potential empathic target. More abstract tasks, like those posed by Eisenberg-Berg, leave open the possibility that empathic reasoning does in fact form a significant part of young children's typical moral reasoning, but its presence is being disguised or depressed by the more cognitively demanding aspects of the task.

Finally, even given the above concerns about experimental design, it is worth noting that Eisenberg-Berg's findings are not in fact (contra Prinz) inconsistent with the idea that empathy is developmentally necessary for morality. For although she finds greater use of empathic reasoning amongst older children, Eisenberg-Berg's conclusion is that:

Empathic moral concerns comprised much of the elementary school and high school subjects' moral reasoning. Indeed, even the second-graders in the present study frequently verbalised much needsorientated reasoning (i.e. statements such as 'I'd help because he's hungry'). Since needs-orientated reasoning intercorrelated with and loaded on the same factor as clearly empathic considerations, it is logical

\footnotetext{
4 The other scenarios were similarly problematic: in the second scenario, an individual is asked to give blood regularly over a period of time, despite suffering serious loss if they do so (they will lose their job, disrupt their studies, etc.). Yet this kind of long-term commitment to providing indirect help to another is not the kind of situation likely to tap empathic moral reasoning amongst younger children, even were it to be a feature of other moral judgements made at this age. The third scenario involved a subject helping another who is being mugged, but this again requires a significant act of mental projection on behalf of the children before they can engage in an empathic response (the children must first imagine that they are someone who is capable of making a difference during a mugging before considering their response to the other, and empathic responses may well be supressed due to fear of physical harm to the self). The fourth and final scenario involved a swimmer choosing between helping disabled children and training to win a swimming competition. While this scenario perhaps gets closest to the kind of situation which might really prompt an empathic response in young children, it still involves comprehension of a complex and unusual situation, mental projection and an empathic response to an imagined other rather than a real subject, all of which might serve to prompt the use of non-empathetic strategies in the moral reasoning of young children.

${ }^{5}$ As things currently stand then, Prinz's suggestion that "empathy enters into moral discourse fairly late in development" (219) might perhaps be thought to run foul of the old adage that absence of evidence is not evidence of absence.
} 
to conclude that such reasoning represents a primitive empathic orientation...[B]oth empirical (Damon [1971]) and anecdotal (Hoffman 1975) evidence support the assertion that empathic responding plays an important role in the early development of a prosocial orientation. (1979: 135-6)

Indeed, this claim forms a key element of what I take to be the main hypothesis of EisenbergBerg's paper, namely that prosocial moral reasoning (where the needs of the subject conflict with the needs of a target in a situation where rules, etc., are not to the fore) may develop in a different way to prohibition moral reasoning (where laws, etc., are to the fore). Since for position (ii) to be viable it need not be that empathy is necessary for all forms of moral development (e.g. if it underpins only prosocial moral reasoning this would, I would suggest, be sufficient), these findings seem at the very least to be consistent with position (ii).

Turning finally to objection (4), Prinz is of course right to note that impairment cases cannot demonstrate conclusively that empathy is necessary for moral development, since the loss of empathy and the loss of moral capacity could well be joint effects of some up-stream impairment. Indeed, in general appeals to impairment cases seem problematic in terms of evidencing a philosophical theory here. For psychopaths present a complex array of behaviours and display a range of deficits which make it unlikely that the condition can be understood in terms of a single dimension of loss along which the psychopathic population can be understood. Given this, the most that could be shown by examination of the psychopathic population would be the negative claim: if a population which is characterised (at least in part) via impairment to or absence of the capacity for empathy were found to have an unimpaired capacity for moral understanding, this would suffice to show that empathy was not necessary for moral understanding. Since this is not what we find with psychopaths, these impairment cases leave open the possibility that empathy is indeed necessary for (some kinds of) moral understanding. Thus, while Prinz is clearly right that none of the points surveyed thus far conclusively show that empathy is necessary for moral development, he is wrong, I think, to claim that the position is ruled out, or indeed that it enjoys little support. First, as Prinz himself notes (2011: 
217), “Conceptually, this idea has much appeal": given that empathy appears to be quite a lowlevel cognitive capacity, and given its connection to an appreciation of the position of another, the idea that empathy could provide a route into moral concern does seem appealing. Second, while Smetana and Braeges (1990) show that the moral/conventional distinction is grasped very early (before the third birthday), there is, as far as I know, no evidence that this predates children's empathic responses. For instance, by one year of age children spontaneously comfort one another on witnessing another's distress (Zahn-Waxler et al 1990) and from a very young age children seek to punish cheats or freeloaders, importantly even if the target has cheated on someone other than themselves (where it is plausible that the conception of the other as the victim in an exchange is grounded at least in part on empathy with the injured party; see Hamlin et al 2007, Hamlin and Wynn 2011). There is no evidence then that moral understanding is developmentally earlier than empathic understanding. Third, as Eisenberg-Berg's findings show, even very young children do use empathetic responses within their moral reasoning and, as I suggested above, her finding that older children apparently have a greater reliance on empathic response may in fact be a construct of the experimental settings in play. Given an easier test, we might well find that empathic reasoning forms a significant part of moral decision making (of the right sort) amongst children of all ages. Furthermore, while studies of impaired populations cannot of course prove a causal connection between empathy and morality, the negative correlation in these cases (where loss of empathy is accompanied by a compromised moral understanding) does serve, I would suggest (contra Prinz 2011), to strengthen a potential inference to the best explanation. Given the evidence that even very young children sometimes use empathic reasoning in prosocial moral decision making, given that older children make extensive use of empathic reasoning in these situations, given the correlation between lack of empathy and impaired moral development, and given the extant conceptual appeal of the position, it is far too early to close the door on the idea that empathy is necessary for (prosocial) moral development. 


\section{3) Moral development in an individual vs. moral development in a species}

Finally, we have been considering the claim that empathy is necessary for moral development, but exactly how should this claim be understood? As noted at the outset, Prinz takes position (ii) to make a diachronic claim about the conditions necessary for development of a moral capacity and he apparently understands this claim in individual terms, i.e. as the question of what is required for a given child to move from a lack of moral capacity to a moral capacity. However it seems that we might also understand position (ii) not in terms of an individualistic reading but rather in terms of a species-level, evolutionary story. In this way, empathy would be held to be a necessary pre-cursor of morality because the moral capacity we as a species enjoy evolved on the back of the capacity for empathy found in our closest evolutionary ancestors.

This, I take it, is the kind of appeal to empathy to be found in the work of Frans de Waal, who has argued at length that human morality needs to be understood in terms of a continuity between our capacities and those to be found amongst apes (and, to a lesser extent, monkeys). According to de Waal "human morality is firmly anchored in the social emotions, with empathy at its core" (2006: 56). De Waal highlights what he calls 'cognitive empathy', i.e. the ability to enact an action plan designed to alleviate the suffering of another for no other reason than the desire to alleviate that suffering, and he argues that this moral emotion can be seen in action in ape behaviour. So a male chimpanzee reaches up to help a distressed youngster out of a tree (2006: 41), a young chimpanzee seeks out and holds a distressed male after the latter's defeat in a fight (2006: 33-4), and so on. These natural, other-directed, apparently empathy-based behaviours are, de Waal suggests, proto-moral: they provide the building blocks from which human morality evolved. ${ }^{6}$

\footnotetext{
${ }^{6}$ In support of this claim, de Waal 2006: 56 argues that "neuroimaging shows that moral judgement in fact involves a wide variety of brain areas, some extremely ancient (Greene and Haidt 2002). In short neuroscience seems to be lending support to human morality as evolutionarily anchored in mammalian society."
} 
Obviously any kind of evolutionary story is just that - a story - and evolutionary claims in general are open to well-known and far from insignificant challenges (see Plotkin 2004). Furthermore, even if we were to embrace this kind of evolutionary story, it would not underpin the strongest reading of the necessity claim in position (ii). For even if we held that our moral capacity (or some aspect of it) did evolve from the empathy-based capacities of our ancestors, this might indicate sufficiency rather than necessity: de facto, human morality required ancestor empathy, but other capacities (perhaps other moral emotions, perhaps something else entirely) might have been able to play the same role were the capacity for empathy to have been absent. Nevertheless by focusing on the role of empathy in the moral development of the individual, Prinz 2011 does seem to neglect a potentially attractive version of position (ii), one which stresses species-level development over individual development.

So where does this leave us? Well, I think a reconsideration of the evidence for a connection between empathy and morality shows that Prinz has ruled out position (ii) too soon. As long as we are clear that position (ii) is proposing a diachronic not a concurrent dependency and that the dependency is limited to certain kinds of moral behaviour (i.e. prosocial not prohibition), then I think (ii) remains an attractive position. Moral understanding does not appear earlier (in developmental terms) than empathic responses, and the evidence that Prinz appeals to to show that younger children do not make appeals to empathic responses in moral decision making is compromised. ${ }^{7}$ Furthermore, older children make significant use of empathic responses in forming moral judgements, and there is evidence for a correlation between a lack of empathy and impaired moral development. Together with the theoretical appeal of the idea that empathic responses provide a first foot-hold for the child on route to moral understanding, all of this is sufficient, I think, to show that the position deserves much fuller exploration. Finally, it might also be the case that the role of empathy in moral development is best understood at a

\footnotetext{
${ }^{7}$ Note that Eisenberg-Berg 1979 is compromised as an evidence source for claims about the absence of young children's use of empathy in moral reasoning. However, showing this was not the aim of Eisenberg-Berg's paper and the work may thus succeed on its own terms (i.e. as an argument that prosocial moral development follows a different trajectory to rule-based moral reasoning).
} 
species, rather than an individual, level: perhaps early-ancestor empathy provided an essential building-block upon which the edifice of human morality could be built. While ape research on the moral emotions remains at a relatively early stage, it is an attractive thought that the kind of complex, other-orientated and apparently empathy-based social behaviour of our nearest evolutionary relatives is continuous with the full-blown moral behaviour which characterises $\operatorname{man}^{8}$

\section{Bibliography}

Blair, R. 1995. A cognitive developmental approach to morality: investigating the psychopath. Cognition 57: 1-29.

Bloom, P. \& T. German. 2000. Two reasons to abandon the false belief test as a test of theory of mind. Cognition 77: B25-B31.

Carr, E. W., Winkielman, P., \& C. Oveis. 2013. Transforming the mirror: power fundamentally changes facial responding to emotional expressions. Journal of Experimental Psychology: General. 1-7. Decety, J. \& C. Lamm. 2006. Human empathy through the lens of social neuroscience. The Scientific World Journal 6: 1146-1163.

De Waal, F. 2006, Primates and Philosophers. Princeton, NJ: Princeton University Press.

Eisenberg-Berg, N. 1979. Development of children's prosocial moral judgement. Developmental Psychology 15: 128-37.

\footnotetext{
8 There is a proviso here: though we might accept that empathy provides a necessary precursor to prosocial moral behaviour, it is not clear that empathy-based behaviour is sufficient to account for all forms of prosocial interaction. The problem, stressed by Tomasello 2014, is that the kinds of prosocial moral behaviour required for advanced social cooperation apparently turn on more cognitively demanding moral emotions, such as a sense of equality or fairness. If this is right, then we might think that ape empathy, though providing an evolutionary key for human prosocial behaviour, cannot alone explain the kind of prosocial moral action which is required for human society. Yet in many ways this conclusion might be attractive: the fundamental building blocks of human prosocial attitudes would, on this model, be shared with our great ape ancestors, but at some point on the evolutionary road, we branched off, able to appreciate more abstract and cognitively demanding concepts like 'just rewards'. It would then be this more abstract kind of moral capacity which allowed uniquely human society to evolve.
} 
Hamlin, J.K., K. Wynn \& P. Bloom. 2007. Social evaluation by preverbal infants. Nature 450: $557-9$

Hamlin, J.K. \& K. Wynn. 2011. Young infants prefer prosocial to antisocial others. Cognitive Development 26: 30-9.

Onishi, k. \& R. Baillargeon. 2005. Do 15 month old infants understand false beliefs? Science 308: $255-258$

Plotkin, H.C. 2004. Evolutionary thought in psychology: a brief history. Malden, Mass.: Wiley-Blackwell. Prinz, J. 2011. Is empathy necessary for morality? In P. Goldie \& A. Coplan (eds) Empathy: Philosophical and Psychological Perspectives. Oxford: Oxford University Press. 211-229.

Simner, M. 1971. Newborn's response to the cry of another infant. Developmental Psychology 5: 13650.

Smetana, J. \& J. Braeges. 1990. The development of toddlers' moral and conventional judgements. Merrill-Palmer Quarterly 36: 329-346.

Thompson, R. 1981. Empathy and emotional understanding: the early development of empathy. In N. Eisenberg \& J. Strayer (eds) Empathy and its Development. Cambridge: Cambridge University Press. 119-45.

Tomasello, M. 2014. A Natural History of Human Thinking. Harvard: Harvard University Press. Zahn-Waxler, C. \& M. Radke-Yarrow. 1990. The origins of empathic concern. Motivation and Emotion 14: 107-130. 